\title{
DYNAMIC RESPONSE OF WIND POWER GENARATORS USING STATCOM
}

\author{
M.Mohammadha Hussaini ${ }^{1}$, Dr. R. Anita ${ }^{2}$ \\ ${ }^{1 \& 2}$ Institute of Road and Transport Technology, EEE Department, Erode, India
}

\begin{abstract}
-
This paper investigates the steady state performance of STATCOM based on 6 pulse voltage sourced converter by which the stator flux oriented vector control of terminal voltage for SEIG is obtained. The complete digital simulation of the STATCOM and wind turbine, self excited induction generator (SEIG) are performed using the power system blockset (PSB) while the control system blockset is modeled using simulink. To increase the transient stability conditions of the generator a statcom is introduced as the active VAR supporter. The paper qualifies and quantifies the improved short term voltage and rotor stability performance obtained when a STATCOM is introduced during different types of failure events in the connected power system.
\end{abstract}

Keywords: wind turbine, SEIG, STATCOM, control of dc voltage.

\section{INTRODUCTION}

The working principle of the wind turbine includesthe following conversion processes: the rotor extracts the kinetic energy from the wind creating genearto torque and the generator converts theis torque into electricity and feeds it into the grid. Presently there are three main turbine types abailable. They are

- Squirrel-cage induction generator

- Doubly fed induction generator.

- Direct-drive synchronous generator.

The first one which is the simplest and oldest system consists of a conventional directly grid-coupled squirrel caged induction generator. The slip, and the result rotor speed of the Generator varies with the amount of power generated . the rotor speed variation is small, approximately $1 \%$ to $2 \%$,and hence this is normally referred as a constant speed turbine.

The other two generationg systems are variable -speed systems. In the doubly fed induction generator, a back to back voltage source converter feeds the three phase rotor winding, Resulting that the mechanical and electrical rotor frequency are decoupled and the electrical stator and rotor frequency can match independently of the mechanical rotor speed. In the direct-drive synchronous generator, the generator is completely decoupled from the grid by power electronics, as a converter is connected to the stator winding and another converter is connected to the grid. Thus the total power delivered by the wind power is transmitted by an HVDC link.

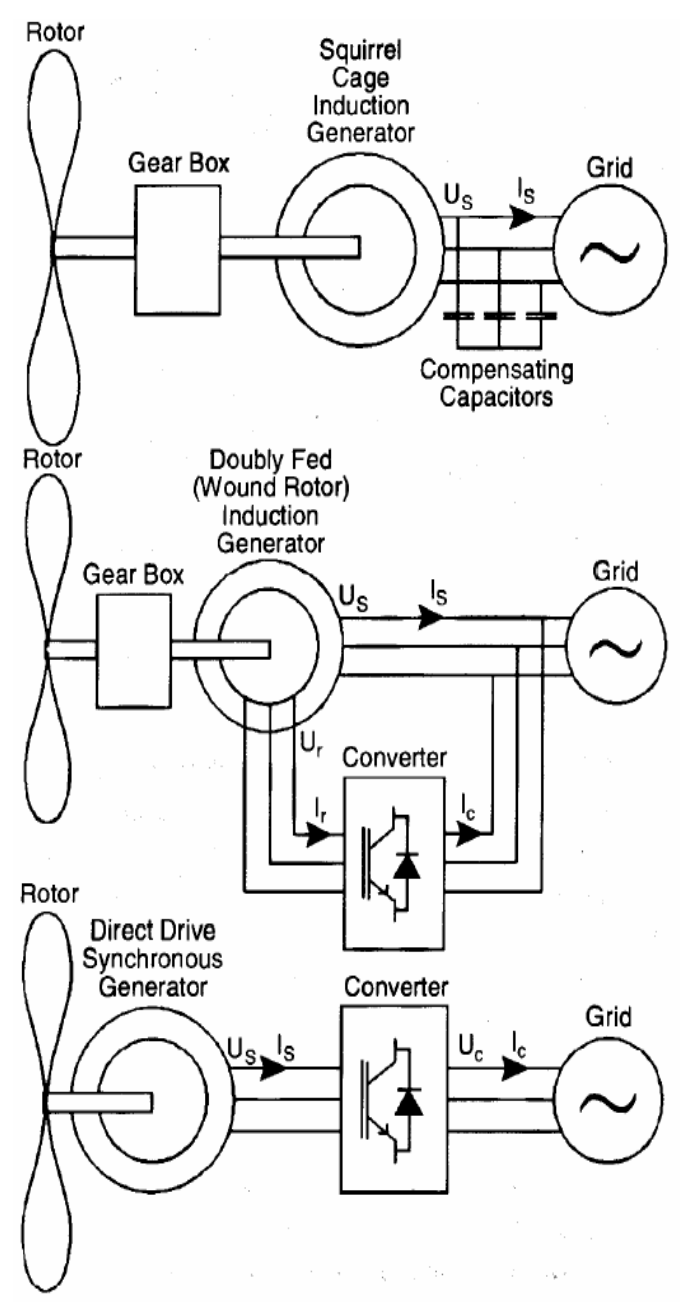

Figure 1: three main generating systems presently used in wind turbines:

Top : Squirrel cage induction generator;

Middle : Doubly fed induction generator;

Bottom : direct-drive synchronous induction generator. 


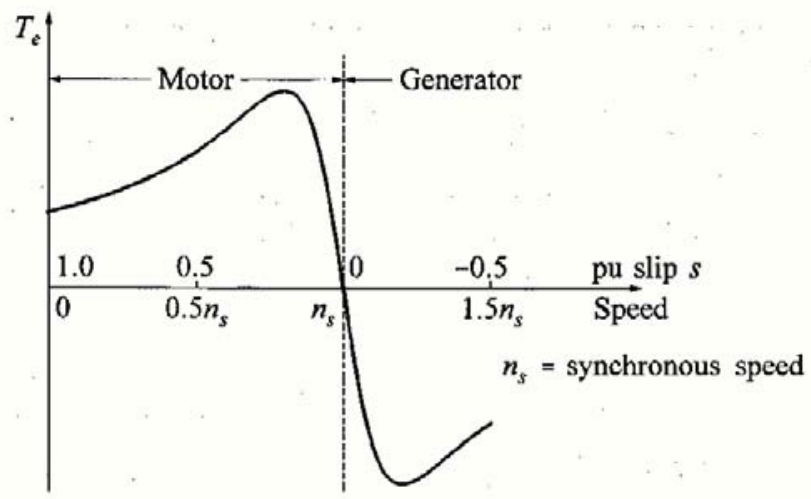

Figure 2: Torque-Speed Characteristics

Considering the SEIG type of wind turbine which is the most commonly used wind turbine (simple and economic) this paper will concentrated on evaluating the performance of this type of generator.

The slip of a motor, $\mathrm{s}$ which is defined as the slip of the rotor with respect to the stator magnetic field, can be given as

$$
\boldsymbol{S}=-\mathrm{Ne}-\mathrm{Nr}
$$

Ne- synchronous speed in rpm

$\mathrm{Nr}-$ rotor speed in rpm.

The speed at which the Rotating magnetic field rotates depends on the supply frequendy. When the rotor totates at a speed less than the speed of the RMF the induction machine acts as a motor. The slip at this point is positive as the rotor speed is less than the stator speed(RMF speed). When the speed of the rotor is greater than the speed of the stator the machine acts as a generator delivering electrical power as output. At this juncture the speed of the rotor is greater than the speed of the stator; hence slip is negative, the RMF can be reversed by interchanging any two terminals of the syooy. While doing so the machine tends to rotate in opposite direction. This region is known as the breaking region. Slip of the machine is greater than one in this region. The torque speed characteristics of the induction.Machine is shown in the figure 2 .

\section{D-Q AXES INDUCTION MACHINE MODEL}

Using D-Q representation the induction machine can be modelled as shown in figure. This representation is a general model based on the assumption that the supply voltage can either be applied to the both the stator and or rotor terminals. In general power can be supplied to the induction machine(motor) or extracted from it (generator). If the electrical power is applied to the induction machine then rotor will start to rotate and the machine is operating as a motor.
On the other hand, if mechanical power is applied to the rotor of the induction machine then machine will convert mechanical power to electrical power. In this case the machine Is operating as an induction generator. When the induction machine is operating as the generator is connected to the grid or supplying an isolated load, driven by an external prime mover, then the rotor should be driven above synchronous speed.

When the machine is operated as a motor, power flows from the stator to the rotor, crossing the airgap.However in generating mode of operation, power flows from the rotor to the stator. Only these two modes are dealt with in this investigation. The braking region where the rotor rotates opposite to the direction of the rotating magnetic field, is not dealt with here. The conventional model and the (D-Q) axes model are the same for steady state analysis.

$$
\left[\begin{array}{c}
v_{q s} \\
v_{d s} \\
v_{q r} \\
v_{d r}
\end{array}\right]=\left[\begin{array}{cccc}
R_{s}+p L_{s} & 0 & p L_{m} & 0 \\
0 & R_{s}+p L_{s} & 0 & p L_{m} \\
p L_{m} & -\omega_{r} L_{m} & R_{r}+p L_{r} & -\omega_{r} L_{r} \\
\omega_{r} L_{m} & p L_{m} & \omega_{r} L_{r} & R_{r}+p L_{r}
\end{array}\right]\left[\begin{array}{l}
i_{q s} \\
i_{d s} \\
i_{q r} \\
i_{d r}
\end{array}\right] \mathrm{I}
$$

where $R_{s}$ - stator winding resistance, $\Omega$

$$
\begin{aligned}
& R_{r} \text { - rotor winding resistance, } \Omega \\
& L_{m} \text { - magnetising inductance, } \mathrm{H} \\
& L_{s} \text { - stator leakage inductance }\left(L_{l s}\right)+\text { magnetising inductance }\left(L_{m}\right), \mathrm{H} \\
& L_{r} \text { - rotor leakage inductance }\left(L_{l r}\right)+\text { magnetising inductance }\left(L_{m}\right), \mathrm{H} \\
& \omega_{r} \text { - electrical rotor angular speed in rad/sec and } p=d / d t, \text { the differential operator. }
\end{aligned}
$$

Using the matrix shown in equation, the d_q representation given below can be redrawn in detain, in a stationary stator reference frame with separate direct and quadrature axes circuits.

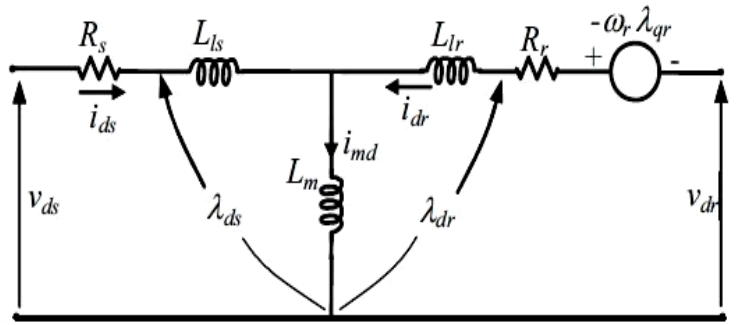

(a)

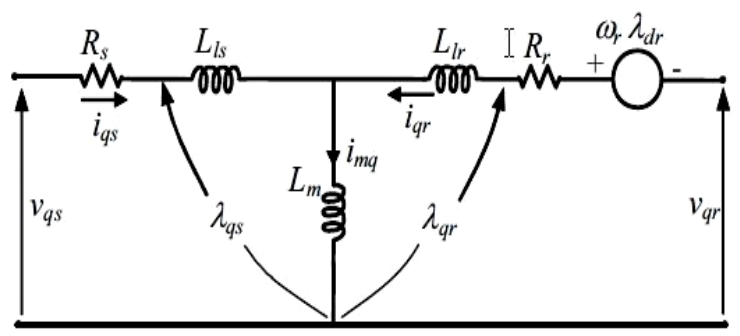

(b) 
Fig: detailed $\mathrm{d}-\mathrm{q}$ representation of induction machine in stationary reference frame (a) d-axes circuit (b) q-axis circuit

From the stator side (for simplicity superscript "s" which indicates stationary reference frame is not included with currents, voltages and flux linkages)

$\lambda_{\mathrm{ds}}=\mathbf{L}_{\mathrm{s}} \mathbf{i}_{\mathrm{ds}}+\mathbf{L}_{\mathrm{m}} \mathbf{i}_{\mathrm{dr}}$

$\lambda_{\mathrm{qs}}=\mathbf{L}_{\mathrm{s}} \mathbf{i}_{\mathrm{qs}}+\mathbf{L}_{\mathrm{m}} \mathbf{i}_{\mathrm{qr}}$

$v_{\mathrm{ds}}=\mathbf{R}_{\mathrm{s}} \mathbf{i}_{\mathrm{ds}}+\mathbf{d} \lambda_{\mathrm{ds}} / \mathbf{d t}$

$v_{\mathrm{qs}}=\mathbf{R}_{\mathrm{s}} \mathbf{i}_{\mathrm{qs}}+\mathbf{d} \lambda_{\mathrm{qs}} / \mathbf{d t}$

from the rotor side

$$
\begin{aligned}
& \lambda_{d r}=L_{m} i_{d r}+L_{r} i_{d r} \\
& \lambda_{q r}=L_{m} i_{q s}+L_{r} i_{q r} \\
& v_{d r}=R_{r} i_{d r}+d \lambda_{d r} / d t+\omega_{r} \lambda_{q r} \\
& v_{q r}=R_{r} i_{q r}+d \lambda_{q r} / d t-\omega_{r}
\end{aligned}
$$

for the air gap flux linkage

$$
\begin{gathered}
\lambda_{d m}=\mathbf{L}_{m} \mathbf{i}_{m d}=L_{m} \mathbf{i}_{d s}+\mathbf{L}_{m} \mathbf{i}_{d r} \\
\lambda_{q m}=\mathbf{L}_{m} \mathbf{i}_{m q}=\mathbf{L}_{m} \mathbf{i}_{q s}+\mathbf{L}_{m} \mathbf{i}_{q r}
\end{gathered}
$$

the stator electrical input powet to the induction machine during motoring iperation or the stator electrical output power in generating mode is given by

$P_{\mathrm{e}}=3 / 2\left(\mathbf{i}_{\mathrm{ds}} \mathbf{v}_{\mathrm{ds}}+\mathbf{i}_{\mathrm{qs}} \mathbf{v}_{\mathrm{qs}}\right)$

The electromagnetic torque Te is given by

$$
\mathbf{T}_{\mathrm{e}}=\mathbf{3} / \mathbf{2} \mathbf{P}_{\mathrm{p}} \lambda_{\mathrm{m}} \times \mathbf{I}_{\mathrm{r}}
$$

Where, $\lambda_{m}-$ air gap flux linkage

$I_{r}$ - rotor current space vector

$P_{p}$-number of pole pairs of the induction machine.

Solving the cross product in Equation gives

$$
\mathrm{T}_{\mathrm{e}}=3 / 2 \mathrm{P}_{\mathrm{p}} \mathrm{L}_{\mathrm{m}}\left(\mathrm{i}_{\mathrm{qs}} \mathrm{i}_{\mathrm{dr}}-\mathrm{i}_{\mathrm{ds}} \mathrm{i}_{\mathrm{qr}}\right)
$$

The mechanical equation in the motoring region is

$$
\mathrm{T}_{\mathrm{e}}=\mathrm{Jd} \omega_{\mathrm{m}} / \mathrm{dt}+\mathrm{D} \omega_{\mathrm{m}}+\mathrm{T}_{\mathrm{m}}
$$

and in the generating region it is given as

$$
\mathrm{T}_{\mathrm{m}}=\mathrm{J} \mathrm{d} \omega_{\mathrm{m}} / \mathrm{dt}+\mathrm{D} \omega+\mathrm{T}_{\mathrm{e}}
$$

Where $T_{m}-$ Mechanical torque in the shaft, $\mathrm{N}_{\mathrm{m}}$

$T_{e}$ - Electromagnetic torque, $\mathrm{N}_{\mathrm{M}}$

$$
\begin{aligned}
& \omega_{m}-\text { Mechanical shaft speed }\left(\omega_{m}=\omega_{\mathrm{r}} / \mathrm{P}_{\mathrm{p}}\right) \mathrm{rad} / \mathrm{sec} \\
& D-\text { Friction coefficient, } \mathrm{N}_{\mathrm{m}} / \mathrm{rad} / \mathrm{sec} \\
& J-\text { Inertia, } \mathrm{Kg}-\mathrm{m}^{2}
\end{aligned}
$$

The mechanical power generated during motoring or the mechanical

power required to drive the induction generator is given by

$$
\mathbf{P}_{\mathbf{m}}=\mathbf{T}_{\mathrm{e}} \boldsymbol{\omega}_{\mathbf{m}}
$$

\section{GENERATOR USING THREE AC CAPACITORS}

Any induction machine requires excitation current to magnetise the core and produce a rotating magnetic field. The excitation current for an induction generator connected to an external source, such as the grid, is supplied from that external source. If this induction generator is driven by a prime mover above the synchronous speed, electrical power will be generated and supplied to the external source. An isolated induction generator without any excitation will not generate voltage and will not be able to supply electric power irrespective of the rotor speed.

In general an induction generator requires reactive power for its operation. Three charged capacitors connected to the stator terminals of the induction generator can supply the reactive power required by the induction generator. Provided that the conditions for self-excitation are satisfied the charged capacitors cause the terminal voltage to build up at the stator terminalsof the induction generator. When the harged capacitors are connected to the terminals a transient exciting current will flow and produce a magnetic flux. This magnetic flux will generate voltage and the generated voltage will be able to build the charge in the capacitors. As the charge increases, more exciting current is supplied to the induction generator. The magnetic flux continues to increase hence producing a higher generated voltage. In this way voltage is built up.

However, if the capacitors are not charged, and a remnant magnetic flux in the core exists, then a small voltage will be generated at the terminals of the induction generator due to that remnant flux. This small voltage will charge the capacitor. The charged capacitor will now be able to produce a small exciting current. With time the exciting current grows and produces magnetic flux more than the remnant magnetic flux and voltage will be built up. This is similar to the the way that current and voltage interact in a resonant circuit. For the voltage to build up across the terminals of the induction 
generator, there are certain requirements for minimum rotor speed and capacitance value that must be met. When capacitors are connected across the stator terminals of an induction machine, driven by an external prime mover, voltage will be induced at its terminals. The induced emf and current in the stator windings will continue to rise until steady state is attained. At this operating point the voltage and current will continue to oscillate at a given peak value and frequency. The rise of the voltage and current is influenced by the magnetic saturation of the machine. In order for self-excitation to occur with a particular capacitance value there is a corresponding minimum speed.

\section{FORMULA FOR CALCULATION OF MINIMUM CAPACITANCE}

$$
C_{\min }=\frac{1}{\omega_{r}^{2} L_{m}}
$$

Where $\omega_{r}$ - the electrical rotor speed. in rad/s

$$
L_{m} \text { - the value of magnetising inductance close to zero voltage. in } \mathrm{H} \text {. }
$$

An important operating characteristics of the SEIG is that This type of generator always consumes reactive power, which is undesirable for the transmission system. In the particualr case of large turbines and weak grid the reactive power consumption is always fully compensated by capacitors in order to achieve a power factor close one.

Another characteristics of SEIG is that in general this type of generator tends to slow down voltage restoration after a fault and this can lead to voltage and rotor speed instability. During a fault the generator will accelerate due to unbalanced load.

\section{A. STATCOM model}

Figure 3 shows the basic model of a STATCOM which is connected to the ac system bus through a coupling transformer. In a STATCOM, the maximum compensating current is independent of system voltage, so it operates at full capacity even at low voltages. A STATCOMs advantages include flexible voltage control for power quality improvement, fast response and applicability for use with high fluctuating loads.

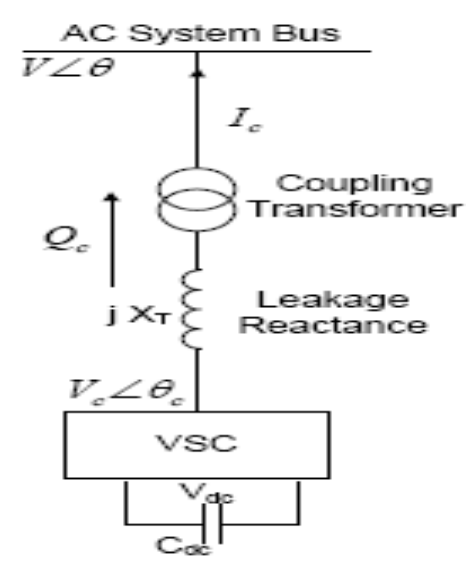

Fig 3. Basic model of a STATCOM

\section{B. Control Scheme}

The STATCOM is a static var generator whose output can be varied so as to maintain or control certain specific parameters of the electric power system. The STATCOM is a power electronic component that can be applied to the dynamic control of the reactive power and the grid voltage. The reactive output power of the compensator is varied to control the voltage at given transmission network terminals, thus maintaining the desired power flows during possible system disturbances and contingencies.

STATCOMs have the ability to address transient events at a faster rate and with better performance at lower voltages than a Static Voltage Compensator (SVC). The maximum compensation current in a STATCOM is independent of the system voltage. A STATCOM provides dynamic voltage control and power oscillation damping, and improves the system's transient stability. By controlling the phase angle, the flow of current between the converter and the ac system are controlled.

A STATCOM was chosen as a source for reactive power support because it has the ability to continuously vary its susceptance while reacting fast and providing voltage support at a local node. Figure shows the block diagram of the STATCOM controller.

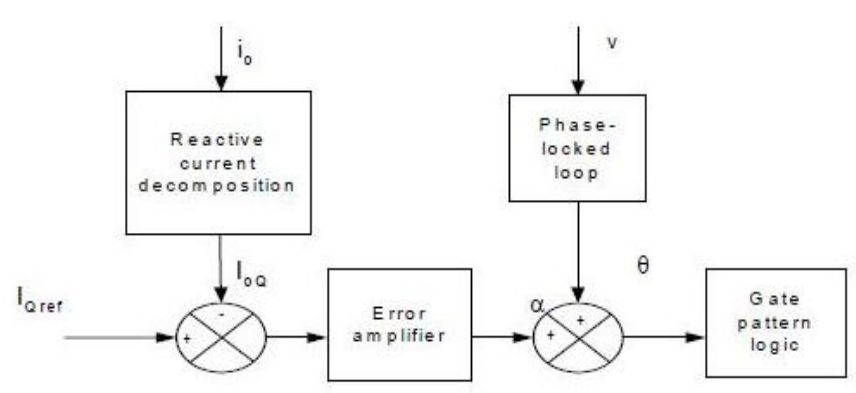

Fig 3 Basic STATCOM control scheme 
A statcom injects almost a sinusoidal current Io of variable magnitude at a point of connection. The injected current is almost in quadrate with the line voltage, $\mathrm{V}$ thereby emulating an inductive or a capacitive reactance at the point of connection with the transmission line. The functionalith of the statcom model is verified by regulating the reactive current flow through it this is usefil to generate or absorb reactive power for regulating the line voltage of the bus where the statcom is connected.

Similarly when the system voltage is higher than the converter voltage, the system "sees" an inductive reactance connected at its terminal. Hence, the STATCOM "sees" the system as the capacitive reactance and the statcom is operating in an inductive mode. The current flows from the ac system to the STATCOM, resulting in the device absorbing reactive power. For an inductive operation the current lags the ac voltage by an angle of 90 degrees, by assuming that converter losses are neglected.

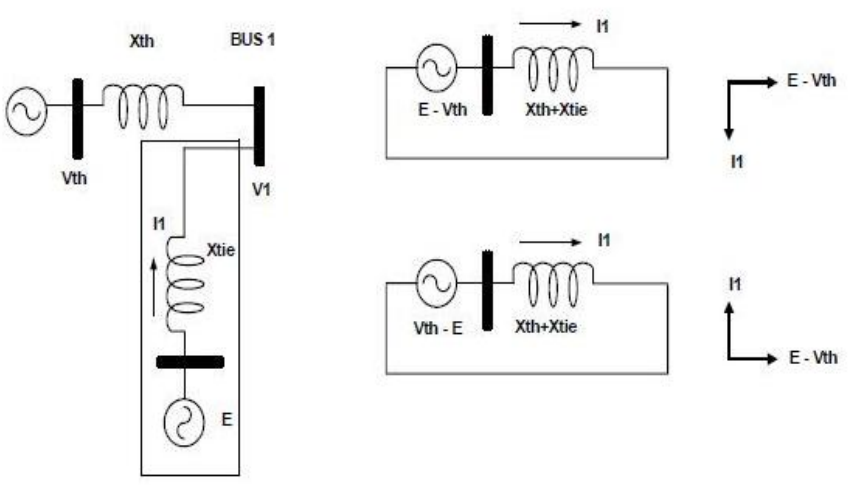

Fig; a static synchronous compensator operated in inductive and capacitive mode.

If the amplitude of the STATCOM output voltage and the ac system voltage are equal, the reactive current is zero ant the STATCOM doesnot generate or absorb reactive powert. Since the STATCOM is generating or absorbing only reactive power the output voltage of the converter, and the ac system voltage $\mathrm{V}$ are in phase when neglecting circuit losses.

The ac current magnitude can be calculated by using the following equation

$$
I_{0}=\frac{V_{\text {out }}-V}{X}
$$

By assuming current flows from converter to the ac system. $\mathrm{X}$ is represented as the coupling transformer leakge reactance. The corresponding reactive power exchanged can be expressed as

$$
Q=\frac{V_{\text {out }}^{2}-V_{\text {out }} V \cos \alpha}{X}
$$

Where angle $\alpha$ is the angle between the ac system bus voltage and the converter output voltage.

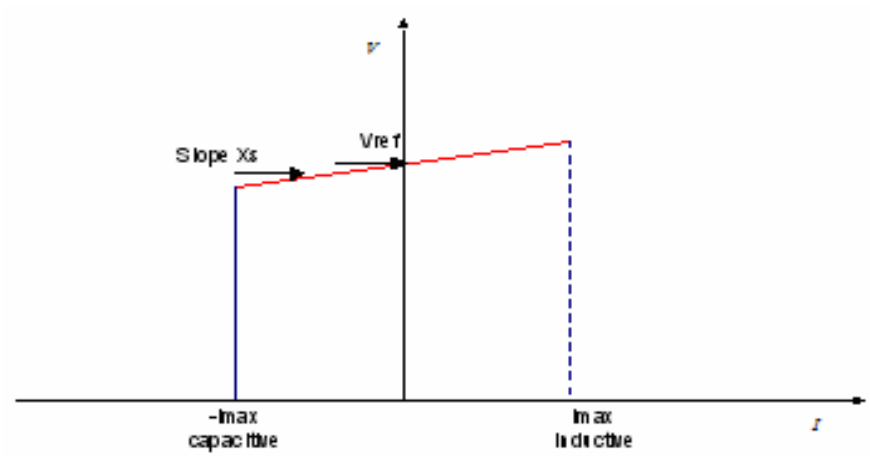

Fig: statcom: V-I characteristics

Where $\mathrm{V}$ : positive sequence voltage(in per unit system)

Vref: is the reference voltage

I: reactive current; ( $\mathrm{I}>0$ indicates an inductive current $\mathrm{I}<0$ indicates a capacitive current) X s: droop reactance;

\section{Simulation results:}

Simulation output for excitation using three capacitors 
M. Mohammadha Hussaini et al. / International Journal of Engineering and Technology Vol.2 (4), 2010, 297-304

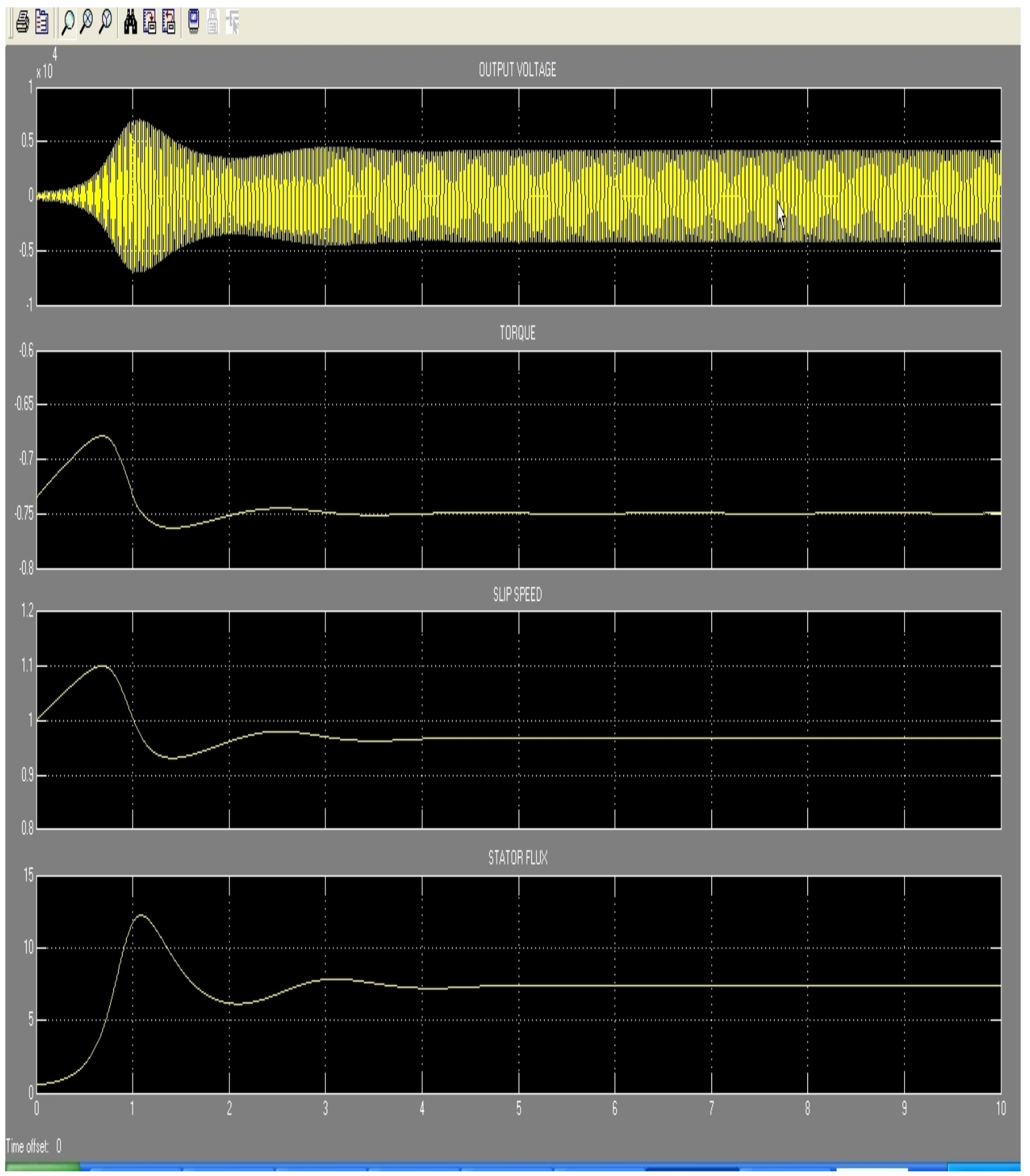

Simulation output for excitation using three capacitors 

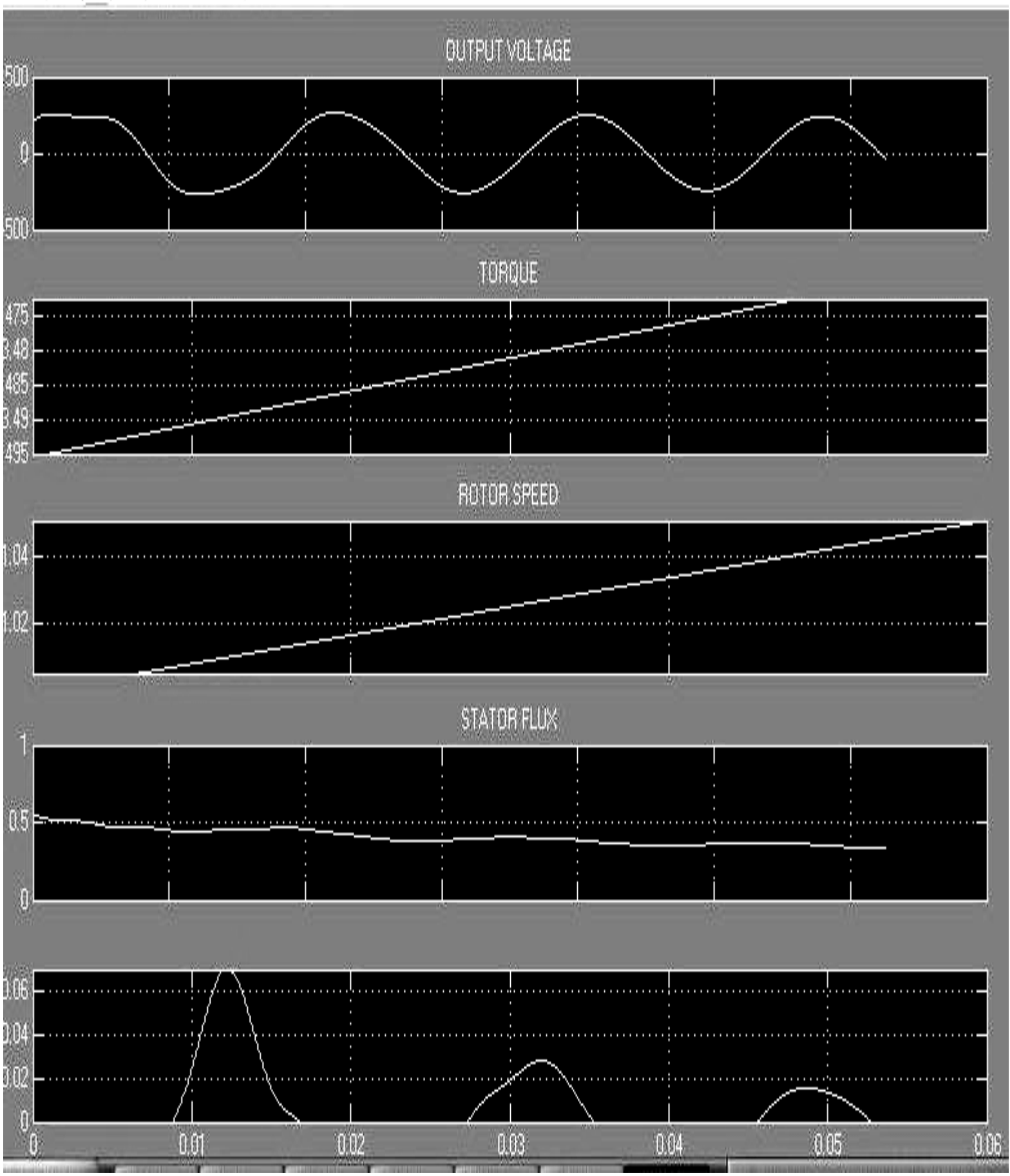

Fig shows the smulation of SEIG with statcom 


\section{DYNAMIC RESPONSE OF STATCOM VOLTAGE;}

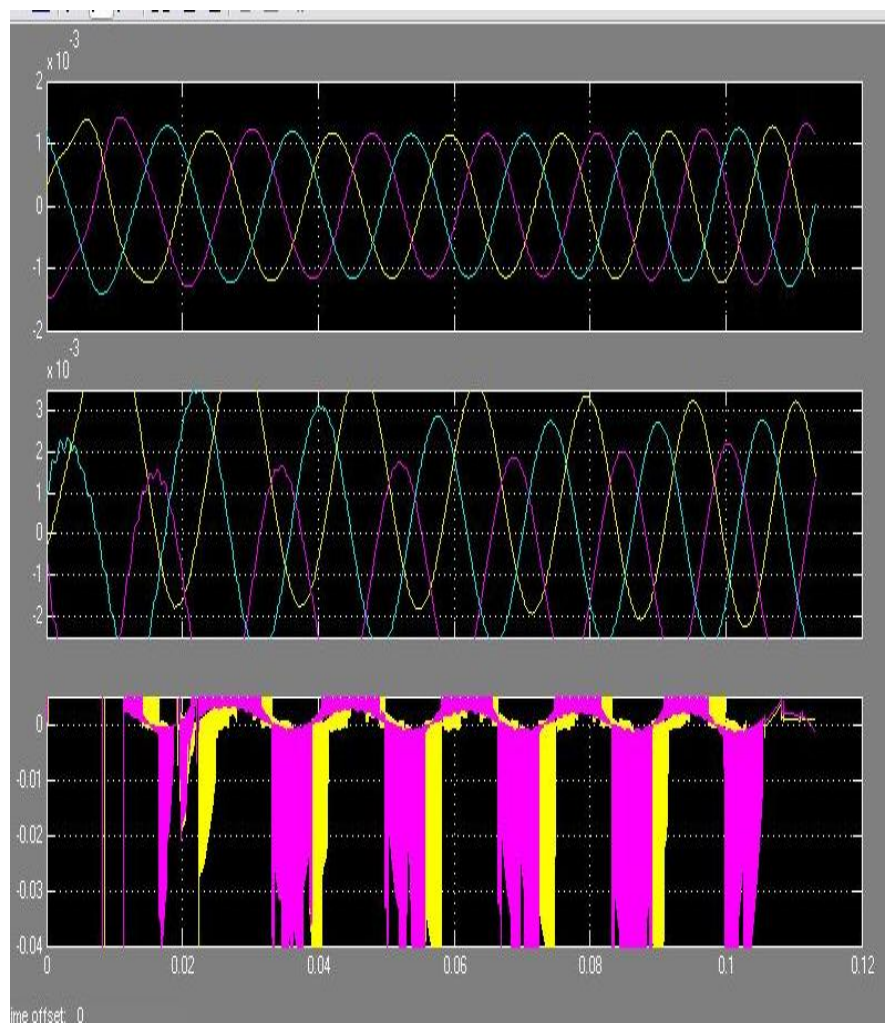

ACTIVE AND REACTIVE POWER

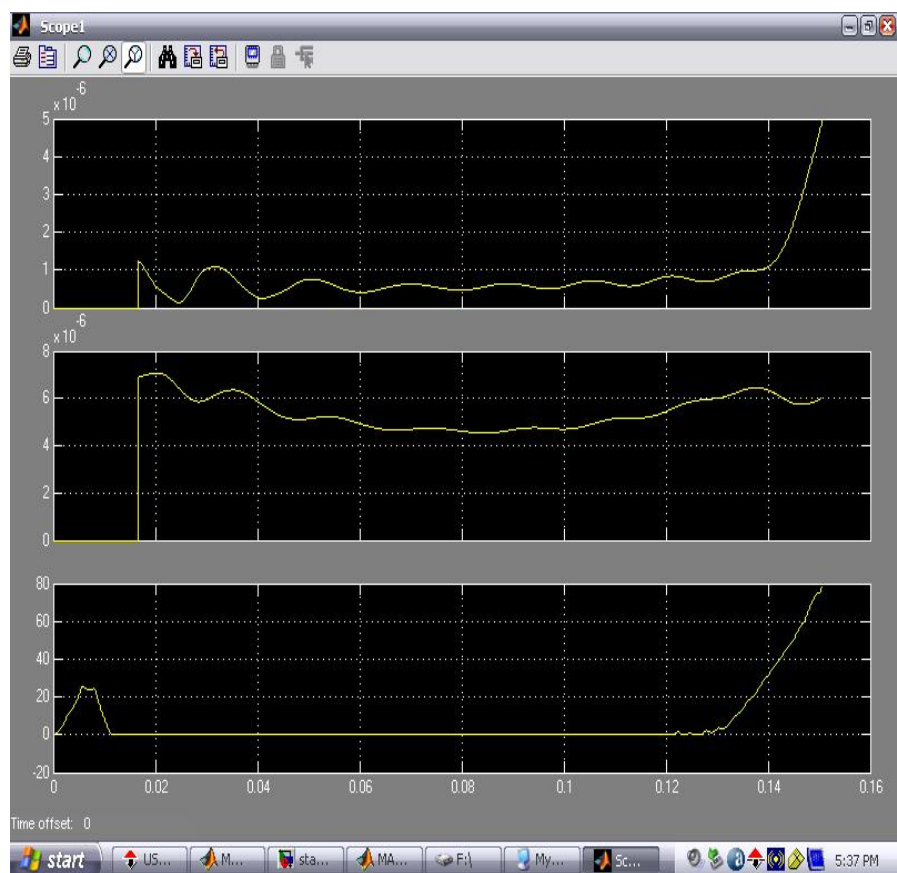

Induction Machine Details:

OUTPUT : $275 \mathrm{KVA}$

VOLTAGE : $480 \mathrm{~V}(\mathrm{~L}-\mathrm{L})$

FREQUENCY : $50 \mathrm{~Hz}$

CONNECTSimulation output for excitation using three capacitors

REFERENCES:

[1]Mrs. M. Mohammadha Hussaini \& Dr. R. Anita "The Study of Dynamic Performance of Wind Farms with the Application of a STATCOM and its Effect"in International Journal of Recent Trends in Engineering, Vol 2, No. 6,November 2009, page no.158-160.

[2] Mrs. M. Mohammadha Hussaini \& Dr. R. Anita "Stator Flux Oriented Self-Excited Induction Generator for Wind Power Applications" in IJJCE, January 2010.

[3] "simulation of a three-level 48 pulses STATCOM" S.Hadjeri, Fatiha Ghezal and S.A. ZIDI.C 2009-Mediamira science publisher.

[4]"steady state performance of static synchronous compensator(STATCOM)" Wahidaah abdul halim, Aida Fazliana abdul kadir, Juifa Mat Lazi; Department of eindustrial power Faculty of electrical engineering KOlej universiti Teknikal kebangsaan Malaysia

[5]"Topic:7wind farm in weak grids compensated with STATCOM" Paulo fisher de Toledo,hailian Xie KTH, Kungl Tekniska hogskolon,EME department, Sweden.

[6]D. Seyoum, C. Grantham and M. F. Rahman, (2003) "The dynamic characteristics of an isolated self-excited induction generator driven by a wind turbine", scheduled for publication in the IEEE Transactions on Industry Applications, Vol. 39, pp. 936 -944.

Authors Biography-

[1] Mrs. M. Mohammadha Hussaini B.E (1991) M.E(Power Systems) 1993 from Thiagarajar College of Engg, Madurai . Published 10 papers in National Conference. Currently as SL/EEE Dept in IRTT, Erode.

[2] Dr. R. Anita B.E (1984)GCT,Cbe, M.E (1990) CIT, Cbe. Ph.D(2002) in Electrical Drives and Control. Currently as Head, Department of EEE, IRTT. Guiding 6 research Scholars. Presented nearly 20 papers in International Conferences. Published 5 Papers in International Journals. 